Pemanfaatan Jurnal Online Perpustakaan BPTP Yogyakarta Dwi Titaningsih, Suharno

Kerja Sama antara SDM Perpustakaan untuk Menuju Layanan Prima dan Unggul Endang Fatmawati

Revitalisasi Peran Perpustakaan Umum bagi Masyarakat Noorika Retno Widuri

Optimalisasi Layanan Penelusuran Sumber-sumber Informasi untuk Mendukung Penulisan Karya Ilmiah Dosen dan Mahasiswa di Perguruan Tinggi Dian Hapsari

Memperkuat Peran Pustakawan dalam Mewujudkan Layanan Perpustakaan Perguruan Tinggi yang Prima dan Unggul Bambang Hermanto

Aktivitas Mahasiswa dalam Membaca Skripsi di Perpustakaan Masriyatun

Budaya Peduli dan Budaya Mutu Melayani di Perpustakaan SMP Negeri 13 Surakarta Menuju Sekolah Menyenangkan Ria Widyawati

Redesain Website UPT Perpustakaan Universitas Sebelas Maret sebagai Media Pendidikan Pengguna bagi Pemustaka Tri Hardian Satiawardana

Peran Perpustakaan dalam Membangun Citra Perpustakaan di Era Teknologi Informasi Sri Anawati

Komunitas Pustakawan Menulis (upaya menyebarluaskan dan melestarikan pengetahuan) Tri Hardiningtyas 


\section{Jurnal}

\section{Pustaka Ilmiah}

\section{Jurnal Ilmiah UPT Perpustakaan UNS}

Jurnal Pustaka Ilmiah (JPI) sebagai media kreasi para pustakawan, guru, dosen, dan praktisi dalam pengembangan profesi secara berkelanjutan. Berbagai ide dan gagasan kreatif menjadi bahan kajian yang diimplementasikan dalam berbagai model pengembangan bahan pustaka, baik cetak maupun online. Kreativitas menjadi akar pengembangan ilmu pengetahuan sepanjang hayat dengan berbagai model pengembangan budaya literasi di perpustakaan. Keindahan dan kecermatan dalam sebuah tulisan ilmiah dan nonilmiah akan dapat direalisasikan secara nyata oleh sumber daya manusia untuk menghasilkan SDM yang unggul dan kreatif dengan membaca dan menulis untuk menyinari dunia. Budaya literasi menjadi upaya untuk pengembangan dan pemberdayaan perpustakaan sebagai pusat sumber belajar untuk mendukung tri dharma perguruan tinggi.

\section{SUSUNAN REDAKSI}

Penanggung Jawab

Ketua Redaksi

Wakil Redaksi

Sekretaris

Penyunting Ahli

Penyunting

Bendahara

Sirkulasi
: Dr. Muhammad Rohmadi, M.Hum.

: Dra. Tri Hardiningtyas, M.Si.

: Haryanto, M.IP.

: Bambang Hermanto, S.Pd., M.IP., Henny Perwitosari, A.Md.

: 1. Dr. Muhammad Rohmadi, M.Hum. (Universitas Sebelas Maret);

2. Drs. Widodo, M.Soc.Sc. (Universitas Sebelas Maret);

3. Drs. Harmawan, M.Lib. (Universitas Sebelas Maret).

: Daryono, S.Sos., M.IP.; RiahWiratningsih, S.S., M.Si., Dinar Puspita Dewi, S.Sos., M.IP.; Sri Utari, S.E.

: Nurul H., A. Md.; Novi Tri Astuti, A.Md.

: Aji Hartono, A. Md.; Agus Sriyono, A.Md.; Aris Suprihadi, S.IP.

UPT PERPUSTAKAAN UNS

REDAKSI JURNAL PUSTAKA ILMIAH

Alamat: Jl. Ir. Sutami 36A Kentingan, Surakarta 57126

Telp./Fax.: (0271) 654311; email: jurnal.pustaka.ilmiah@gmail.com 


\section{Pengantar Redaksi}

\section{Salam Pustaka.}

Dengan mengucap rasa syukur kepada Allah SWT. segenap Tim Redaksi Jurnal Pustaka Ilmiah (JPI) mengucapkan banyak terima kasih kepada para penulis yang telah berkontribusi untuk penerbitan JPI volume 2 edisi Juni 2016. Penerbitan volume 2 kali ini JPI mengetengahkan tema: Pengembangan Perpustakaan menuju Layanan Prima dan Unggul. Kehadiran JPI diharapkan dapat dijadikan sebagai media penulisan bagi para pustakawan, dosen, tenaga kependidikan, guru, dan praktisi untuk menuangkan ide dan gagasan kreatifnya secara tertulis.

Dalam penerbitan JPI volume 2 bulan Juni 2016 ini disajikan sepuluh tulisan antara lain: (1) Pemanfaatan Jurnal Online Perpustakaan BPTP Yogyakarta (Dwi Titaningsih dan Suharno), (2) Kerja Sama Antara Sumber Daya Manusia Perpustakaan untuk Menuju Layanan Prima dan Unggul (Endang Fatmawati), (3) Revitalisasi Peran Perpustakaan Umum Bagi Masyarakat (Noorika Retno Widuri), (4) Optimalisasi Layanan Penelusuran Sumber-Sumber Informasi untuk Mendukung Penulisan Karya Ilmiah Dosen dan Mahasiswa di Perguruan Tinggi (Dian Hapsari), (5) Memperkuat Peran Pustakawan dalam Mewujudkan Layanan Perpustakaan Perguruan Tinggi yang Prima dan Unggul (Bambang Hemanto), (6) Aktivitas Mahasiswa dalam Membaca Skripsi di Perpustakaan FISIP-UNS (Masriyatun), (7) Budaya Peduli dan Budaya Mutu Melayani di Perpustakaan SMP Negeri 13 Surakarta Menuju Sekolah Menyenangkan (Ria Widyawati), (8) Redesain Website UPT Perpustakaan Universitas Sebelas Maret Surakarta sebagai Media Pendidikan Pengguna Bagi Pemustaka (Tri Hardian Satiawardana), (9) Peran Perpustakaan dalam Membangun Citra Perpustakaan di Era Teknologi Informasi (Sri Anawati), (10) Komunitas Pustakawan Menulis : upaya menyebarluaskan dan melestarikan pengetahuan (Tri Hardiningtyas).

Akhirnya, redaksi JPI mengucapkan banyak terima kasih kepada Kepala UPT Perpustakaan UNS yang telah memberikan dukungan dan memfasilitasi untuk penerbitan JPI. Selain itu, ucapan terima kasih juga disampaikan kepada para penulis, tim redaksi, dan Yuma Pressindo, yang telah mempersiapkan dari awal sampai terbitnya JPI. Selamat membaca.

Surakarta, Juni 2016

Ketua Redaksi 


\section{Sambutan}

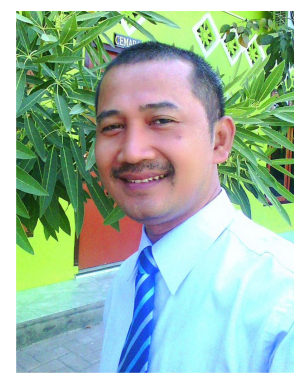

Dr. Muhammad Rohmadi, M.Hum.

\section{Kepala UPT Perpustakaan UNS}

Selamat dan sukses atas diterbitkannya kembali Jurnal Pustaka Ilmiah (JPI). Jurnal ini sebagai media kreativitas dan pengembangan softs skills para pustakawan, guru, dosen, dan praktisi untuk menuangkan ide dan gagasan demi layanan perpustakaan yang prima dan unggul. Berbagai isu terkait dengan pengembangan perpustakaan, pelayanan perpustakaan sebagai pusat sumber belajar, pendidikan, penelitian, pelestarian, dan budaya literasi akan menjadi topik-topik yang disajikan dalam jurnal ilmiah ini.

Diterbitkannya JPI sebagai bukti kepedulian UPT Perpustakaan Universitas Sebelas Maret Surakarta (UNS) dalam rangka turut berpartisipasi mengembangkan dan membudayakan literasi untuk para pustakawan dan civitas akademika di UNS maupun luar UNS. Berbagai model pengembangan softs skills menjadi alternatif untuk membekali dan memperkuat jaringan kerja sama penulisan antar kelembagaan. Dengan demikian, kerja sama antar pustakawan dan pemustaka dapat diwujudkan dengan berbagai model dalam bidang literasi.

Penerbitan JPI merupakan sarana untuk memotivasi semua pustakawan agar berkarya di bidang penulisan, baik ilmiah maupun nonilmiah. Para pustakawan harus menjadi pionir dalam bidang penulisan. Hal ini sebagai bentuk kepedulian dan keteladaan para pustakawan yang memproses, menyajikan, dan menikmati bahan-bahan pustaka cetak dan noncetak di perpustakaan. Ketersedian bahan pustaka akan menjadi bahan paling nyata untuk dikembangkan dalam berbagai model perwujudan teknik penulisan. Hal terpenting yang harus dimiliki oleh para pustakawan adalah semangat untuk berbagi pengetahuan melalui tulisan.

Kepedulian setiap sumber daya manusia kepada kelembagaan dapat dituangkan dalam berbagai model pengabdian, salah satunya adalah melalui tulisan. Berbagai ide dan gagasan dapat direalisasikan dengan berbagai model bentuk artikel jurnal, buku, modul, monograf, dan lain sebagainya. Para civitas akademika, guru, praktisi harus memiliki keterampilan menulis sebagai bentuk perwujudan pengembangan diri secara berkelanjutan. Berbagai tulisan dan referensi sudah disajikan tetapi masih sangat minim untuk diimplementasikan dalam kehidupan. Banyak orang pandai dalam berbicara tetapi masih sedikit yang menuangkan ide dan gagasannya dalam bentuk tulisan.

Akhirnya, keluarga besar UPT Perpustakaan UNS mengucapkan banyak terima kasih kepada Rektor, Wakil Rektor, pengelola JPI, penulis, dan semua pihak yang telah mendukung penerbitan JPI. Semoga dengan diterbitkannya JPI ini dapat menjadi media untuk menulis para pustakawan, dosen, guru, dan praktisi dalam bidang iptek dan seni. Ucapan terima kasih juga diucapkan kepada percetakan Yuma Pressindo yang telah membantu mempersiapkan dari awal sampai terbitnya JPI ini. Akhirnya, semoga JPI dapat memberikan nilai kemaslahatan untuk umat. 


\section{DAFTAR ISI}

\section{JURNAL PUSTAKA ILMIAH EDISI KEDUA: VOLUME 1 NOMOR 2/ JUNI 2016}

\section{Tema: Pengembangan Perpustakaan Menuju Layanan Prima dan Unggul}

Pemanfaatan Jurnal Online Perpustakaan BPTP Yogyakarta

Dwi Titaningsih, Suharno

Kerja Sama antara SDM Perpustakaan untuk Menuju Layanan Prima dan Unggul

Endang Fatmawati

Revitalisasi Peran Perpustakaan Umum bagi Masyarakat.

Noorika Retno Widuri

Optimalisasi Layanan Penelusuran Sumber-sumber Informasi untuk Mendukung Penulisan Karya Ilmiah Dosen dan Mahasiswa di Perguruan Tinggi..

Dian Hapsari

Memperkuat Peran Pustakawan dalam Mewujudkan Layanan Perpustakaan Perguruan Tinggi yang Prima dan Unggul.

Bambang Hermanto

Aktivitas Mahasiswa dalam Membaca Skripsi di Perpustakaan

Masriyatun

Budaya Peduli dan Budaya Mutu Melayani di Perpustakaan SMP Negeri 13 SurakartaMenuju SekolahMenyenangkan.

Ria Widyawati

Redesain Website UPT Perpustakaan Universitas Sebelas Maret sebagai Media Pendidikan Pengguna bagi Pemustaka.

Tri Hardian Satiawardana

Peran Perpustakaan dalam Membangun Citra Perpustakaan di Era Teknologi Informasi

Sri Anawati

Komunitas Pustakawan Menulis (upaya menyebarluaskan dan melestarikan pengetahuan)

Tri Hardiningtyas 


\title{
BUDAYA PEDULI DAN BUDAYA MUTU MELAYANI DI PERPUSTAKAAN SMP NEGERI 13 SURAKARTA MENUJU SEKOLAH MENYENANGKAN
}

\author{
Ria Widyawati \\ SMP Negeri 13 Surakarta \\ Email: ia_widyawati@yahoo.co.id
}

\begin{abstract}
Students of SMP Negeri 13 Surakarta mostly students from families with lower economic level. Most students of SMP Negeri 13 Surakarta not yet have adequate facilities for the needs of their schools at home, for example a computer or netbook, books that support learning in schools, and other school supplies. Existing facilities at the school became one of the alternatives that can help students to improve students' quality of human resources. Library SMP Negeri 13 Surakarta has the facilities and infrastructure that can help the students to follow the teaching and learning process in schools. Concern antarsiswa and concerns of the student teachers are needed in the environment of SMP Negeri 13 Surakarta because a lot of students that should be redirected in order to achieve future aspired. Library SMP Negeri 13 Surakarta also constantly improve the quality of services that the students and teachers as library members feel comfortable using the library of SMP Negeri 13 Surakarta. Quality culture serves in the library of SMP Negeri 13 Surakarta realized by improving the quality of services to library patrons, for example the use of an application library to replace the use of the manual on the process of borrowing and returning books as well as data members of the library, so as to realize the school a fun and students can enjoy the learning process, feel comfortable in the environment of SMP Negeri 13 Surakarta, especially if students are in the library.
\end{abstract}

Keywords: libraries, care, quality

\begin{abstract}
ABSTRAK
Siswa SMP Negeri 13 Surakarta kebanyakan merupakan siswa dari keluarga dengan tingkat ekonomi menengah ke bawah. Kebanyakan siswa SMP Negeri 13 Surakarta belum memiliki fasilitas yang memadai untuk kebutuhan sekolah mereka di rumah, misalkan komputer atau netbook, buku-buku yang menunjang pelajaran di sekolah, dan perlengkapan sekolah lainnya. Fasilitas yang ada di sekolah menjadi salah satu alternatif yang dapat membantu siswa untuk meningkatkan mutu SDM siswa. Perpustakaan SMP Negeri 13 Surakarta memiliki sarana dan prasarana yang dapat membantu siswa siswi untuk mengikuti proses belajar-mengajar di sekolah. Kepedulian antarsiswa dan kepedulian guru terhadap siswa sangat dibutuhkan di lingkungan SMP Negeri 13 Surakarta karena banyak dari siswa yang harus diarahkan agar dapat meraih masa depan yang dicita-citakan. Perpustakaan SMP Negeri 13 Surakarta juga senantiasa meningkatkan mutu pelayanan agar siswa dan guru sebagai anggota perpustakaan merasa nyaman menggunakan perpustakaan SMP Negeri 13 Surakarta. Budaya mutu melayani di perpustakaan SMP Negeri 13 Surakarta diwujudkan dengan peningkatan mutu layanan kepada pengunjung perpustakaan, misalkan penggunaan aplikasi perpustakaan untuk mengganti penggunaan manual pada proses peminjaman
\end{abstract}


dan pengembalian buku serta data anggota perpustakaan, sehingga dapat mewujudkan sekolah yang menyenangkan dan siswa dapat menikmati proses pembelajaran, merasa nyaman berada di lingkungan SMP Negeri 13 Surakarta, terutama jika siswa berada di ruang perpustakaan.

Kata kunci: perpustakaan, peduli, mutu

\section{PENDAHULUAN}

Peningkatan sarana dan prasarana sekolah merupakan salah satu upaya yang dilakukan sekolah untuk meningkatkan mutu pendidikan. Berbagai upaya peningkatan mutu terus dilakukan, baik dari pemerintah maupun dari pihak sekolah. Penggunaan teknologi informasi dan komunikasi di sekolah juga semakin ditingkatkan dalam pengolahan data siswa, penggunaan teknologi di perpustakaan sekolah, dan penggunaan internet di sekolah. Kemajuan dalam proses pengolahan data menjadi informasi menjadi lebih cepat dan dapat dilakukan secara otomatis. Perpustakaan bukanlah hal yang baru dalam kehidupan sehari-hari. Mulai dari perpustakaan yang ada di lingkungan sekitar kita, perpustakaan pribadi milik perseorangan, dan perpustakaan sekolah yang ada di setiap sekolah, mulai dari sekolah dasar sampai tingkat perguruan tinggi. Perpustakaan sekolah telah diselenggarakan, baik sekolah tersebut negeri ataupun swasta, sekolah umum maupun kejuruan, baik sekolah dasar maupun menengah. Banyak orang yang telah mengetahui, bahkan sering mengunjungi perpustakaan, tetapi salah dalam mendefinisikan pengertian perpustakaan yang sebenarnya. Banyak orang yang mengasosiasikan perpustakaan dengan tumpukan buku pada suatu tempat tertentu. Padahal tidak semua tumpukan buku dikatakan perpustakaan. Salah satu ciri perpustakaan adalah adanya bahan pustaka atau sering juga disebut koleksi pustaka, tetapi masih ada ciriciri lainnya yang lebih mengarah kepada arti perpustakaan.

Siswa SMP Negeri 13 Surakarta kebanyakan merupakan siswa dari keluarga dengan tingkat ekonomi menengah ke bawah. Kebanyakan siswa SMP Negeri 13 Surakarta belum memiliki fasilitas yang memadai untuk kebutuhan sekolah mereka di rumah, misalkan komputer atau netbook, buku-buku yang menunjang pelajaran di sekolah, dan perlengkapan sekolah lainnya. Fasilitas yang ada di sekolah menjadi salah satu alternatif yang dapat membantu siswa untuk meningkatkan mutu SDM siswa. Perpustakaan SMP Negeri 13 Surakarta memiliki sarana dan prasarana yang dapat membantu siswa untuk mengikuti proses belajar-mengajar di sekolah. Tetapi di sisi lain, ada beberapa kekurangan yang membuat Perpustakaan SMP Negeri 13 Surakarta belum dapat melayani para siswa atau guru yang meminjam atau mengembalikan buku perpustakaan.

Perpustakaan SMP Negeri 13 Surakarta masih menggunakan cara manual dalam pengelolaannya. Sistem sirkulasi peminjaman dan pengembalian buku masih dengan cara sederhana tanpa menggunakan teknologi sama sekali, yaitu dengan pencatatan pada kertas. Hal ini tentu saja mempunyai banyak kelemahan, terutama apabila ada catatan untuk pengembalian dan peminjaman buku yang hilang, akan susah melacaknya. Begitu juga apabila ada banyak pengunjung perpustakaan, yaitu siswa yang akan meminjam ataupun mengembalikan di waktu yang sama, yaitu pada saat istirahat yang hanya sekitar lima belas menit. Belum ada kesadaran dari siswa ataupun guru untuk memanfaatkan perpustakaan secara maksimal, misalnya dengan membaca koleksi buku di perpustakaan.

Kepedulian antarsiswa dan kepedulian guru terhadap siswa sangat dibutuhkan di lingkungan SMP Negeri 13 Surakarta karena banyak dari siswa SMP Negeri 13 Surakarta yang harus 
diarahkan agar dapat meraih masa depan yang dicita-citakan. Perpustakaan SMP Negeri 13 Surakarta juga senantiasa meningkatkan mutu pelayanan agar siswa dan guru sebagai anggota perpustakaan merasa nyaman menggunakan perpustakaan SMP Negeri 13 Surakarta.

Berdasarkan latar belakang yang telah dijelaskan di atas, dapat dirumuskan permasalahan sebagai berikut: bagaimanakah upaya melaksanakan budaya peduli dan budaya mutu melayani di perpustakaan SMP Negeri 13 Surakarta menuju sekolah menyenangkan? Ada pun tujuan penulisan naskah ini adalah untuk melaksanakan budaya peduli dan budaya mutu melayani di perpustakaan SMP Negeri 13 Surakarta.

Metode pengumpulan data yang digunakan dalam penulisan ini adalah metode kajian kepustakaan, yaitu suatu teknik mengumpulkan data yang diambil dari kepustakaan (buku, dokumen, artikel, jurnal, laporan, web atau internet, dan lainnya).

\section{Budaya Peduli}

Budaya peduli sering disebut ide atau gagasan, yaitu inti dari budaya. Budaya peduli merupakan satu tatanan gagasan yang mendorong seseorang untuk merasa memiliki. Dalam pandangan Jawa, budaya peduli diartikan rumongso melu handarbeni. Peduli, salah satu kata kerja yang memiliki arti mengindahkan, memerhatikan, menghiraukan. Kata peduli sudah terlalu awam untuk didengar, terlebih dalam kehidupan yang semakin modern seperti saat ini. Terlalu terbiasa indra pendengaran ini menangkap suara-suara orang menyebutkan kata peduli.

Di dalam berbagai jenis kata dalam bahasa Indonesia, peduli termasuk kata kerja di mana bila diucapkan menunjukkan suatu perbuatan atau tindakan. Namun, apakah peduli sudah lebih dari sebuah kata kerja? Lebih dari sebuah kata, sebenarnya bisa menjadi sebuah tindakan yang memiliki pelajaran bermakna. Sudah dijelaskan sebelumnya mengenai arti kata peduli, dapat diketahui peduli memberi arti sebuah tindakan yang tidak bisa dilakukan sendirian atau individu. Untuk peduli, minimal seorang memerlukan objek lain untuk 'dipedulikan'. Sebaliknya, agar kita 'dipedulikan', maka harus ada objek lain yang memedulikan atau memerhatikan kita.

Dalam pemahaman lain, tindakan peduli memberi pelajaran sebagai makhluk sosial untuk tidak berpaham individualisme. Sejalan dengan arus globalisasi dan modernitas yang semakin maju, diikuti dengan teknologi yang semakin canggih menimbulkan fenomenafenomena sosial di sekitar lingkungan kita, dimana fenomena sosial tersebut dapat memengaruhi kebudayaan masyarakat, khususnya kebudayaan masyarakat Indonesia. Budaya masyarakat saling membantu, prihatin, dan saling peduli. Peduli menjadi salah satu kebudayaan masyarakat tradisional Indonesia. Masyarakat yang masih memegang teguh tradisi dan tinggal di daerah masih memiliki rasa peduli yang tinggi. Fenomena-fenomena sosial yang kian merasuk dalam kebudayaan masyarakat tradisional dan hal tersebut tak bisa diingkari oleh setiap makhluk di muka bumi.

Dari faktor keuntungan, kemajuan teknologi dan globalisasi memberi banyak makrifat dan manfaat bagi banyak pihak. Namun, dari faktor keburukan, terdapat beberapa dampak negatif yang berjalan beriringan dengan dampak positif. Masyarakat bersifat individualis, berpikir pendek, dan kurang peduli. Dampak-dampak seperti inilah yang seharusnya menjadi koreksi bagi berbagai pihak yang turut merasakan globalisasi. Untuk itu, tindakan peduli perlu dilakukan, untuk menghindari dampak negatif dan meraih hal positif dalam globalisasi. Dari penjelasan di atas, dapat disimpulkan bahwa peduli adalah salah satu budaya yang dimiliki oleh masyarakat Indonesia yang memegang teguh tradisi tradisional Indonesia, budaya peduli masyarakat Indonesia tercermin dari 
masyarakat yang saling membantu, menjauhi sifat individualisme dalam hidup bermasyarakat.

\section{Budaya Mutu Melayani}

Pengertian mutu memiliki konotasi yang bermacam-macam tergantung orang yang memakainya. Kata mutu diambil dari bahasa latin qualis, yang artinya what kind of (tergantung dengan kata apa yang mengikutinya). Pengertian mutu sendiri menurut Deming ialah kesesuaian dengan kebutuhan. Sedangkan menurut Juran, mutu ialah kecocokan dengan kebutuhan. Sallis (2003) mengemukakan bahwa mutu adalah konsep yang absolut dan relatif. Mutu yang absolut adalah mutu yang mempunyai idealisme tinggi dan berstandar tinggi yang harus dipenuhi, dengan sifat produk bergengsi yang tinggi. Sedangkan mutu relatif adalah sebuah alat yang sudah ditetapkan dan harus memenuhi standar yang telah dibuat.

Pengembangan budaya mutu melayani di sekolah dilakukan dalam rangka mencapai keefektifan pendidikan di sekolah. Mutu melayani siswa oleh guru dapat dijadikan sebagai salah satu langkah agar siswa merasa nyaman selama mengikuti proses belajarmengajar di sekolah. Perpustakaan SMP Negeri 13 Surakarta selalu meningkatkan mutu pelayanan agar anggota perpustakaan yang terdiri dari guru dan siswa di lingkungan sekolah dapat menggunakan perpustakaan secara maksimal sebagai gudang ilmu.

\section{Sekolah Menyenangkan}

Sekolah menyenangkan adalah sekolah yang memberikan tantangan bagi siswa. Dengan kata lain, sekolah yang menyenangkan dapat diartikan sebagai wahana yang aman dan menyehatkan, serta memberikan pilihan tantangan yang bermakna bagi siswa. Demikian disampaikan Menteri Pendidikan dan Kebudayaan (Mendikbud), Anies Baswedan, pada acara Penutupan Rembuk Nasional Pendidikan dan Kebudayaan (RNPK) tahun 2015, di Depok, Selasa (31/3/2015). Mendikbud menyampaikan, salah satu prinsip sekolah menyenangkan adalah pembelajaran dengan ragam pilihan tantangan, di mana masingmasing siswa diberikan pilihan dan tantangan yang sesuai. Mendikbud mengungkapkan, prinsip sekolah menyenangkan selanjutnya adalah pembelajaran yang memberikan makna.

Pembelajaran yang berguna untuk jangka panjang dan terkait dalam pemecahan masalahmasalah secara nyata. Pembelajaran ini mengajak para guru agar dapat merangsang siswanya dengan pertanyaan-pertanyaan yang subtantif karena pertanyaan subtantif dapat mengarahkan pada inspirasi sehingga benarbenar menjadi wahana belajar yang baik.

Prinsip yang mendasari sekolah menjadi menyenangkan adalah semua ikut terlibat, baik siswa, guru, orang tua, dan kepala sekolah. Dari penjelasan di atas, dapat disimpulkan bahwa sekolah menyenangkan adalah wahana pendidikan yang membuat siswa merasa nyaman berada di sekolah dan dapat meningkatkan kemampuan berpikir siswa dengan merangsang siswa agar memunculkan kreativitasnya dalam menjawab pertanyaan- pertanyaan yang diajukan oleh guru.

\section{PEMBAHASAN}

Perpustakaan SMP Negeri 13 Surakarta terletak di dalam gedung sekolah SMP Negeri 13 Surakarta, yang beralamat di Jalan Urip Sumoharjo 49 Surakarta. Letak SMP Negeri 13 Surakarta yang berada hampir di pinggir kota Solo, juga berdampak pada penerimaan siswa yang kebanyakaan berasal dari keluarga menengah ke bawah, dengan berbagai permasalahan di dalamnya, sehingga penggunaan teknologi di lingkungan SMP Negeri 13 Surakarta masih belum maksimal, karena belum ada dukungan dari orang tua siswa.

Sejak tahun 2014, teknologi mulai berkembang di lingkungan SMP Negeri 13 Surakarta. Beberapa titik telah di pasang wifi 
untuk koneksi internet, begitu juga dengan perpustakaan SMP Negeri 13 Surakarta. Hal ini sangat membantu siswa dalam menyelesaikan tugas sekolah yang berhubungan dengan penggunaan internet untuk mencari informasi. Perpustakaan juga menyediakan lima komputer yang dapat dipakai siswa dengan jadwal yang telah ditetapkan oleh sekolah. Rasa saling peduli di lingkungan SMP Negeri 13 Surakarta harus selalu diterapkan agar dapat saling membantu antarsiswa ataupun guru terhadap siswa. Berikut adalah gambaran singkat tentang budaya peduli dan budaya mutu melayani di perpustakaan SMP Negeri 13 Surakarta.

\section{Budaya Peduli di Perpustakaan SMP Negeri 13 Surakarta}

Kepedulian perpustakaan SMP Negeri 13 Surakarta diwujudkan dengan adanya peminjaman buku untuk seluruh siswa, yaitu buku pelajaran. Para siswa SMP Negeri 13 Surakarta tidak perlu membeli buku pelajaran sekolah karena dari pihak sekolah mengetahui bahwa sebagian besar siswanya berasal dari keluarga yang tidak mampu atau ekonomi menengah ke bawah. Selain itu, perpustakaan SMP Negeri 13 Surakarta juga menyediakan lima komputer yang dapat digunakan sewaktuwaktu oleh siswa. Banyak dari siswa SMP Negeri 13 Surakarta belum memiliki komputer di rumahnya sehingga adanya komputer di perpustakaan sangat membantu siswa dalam mengerjakan tugas sekolah yang diberikan oleh guru.

Perpustakaan SMP Negeri 13 Surakarta juga menyediakan buku-buku fiksi dan nonfiksi sebagai buku bacaan siswa pada waktu jam membaca di pagi hari. Dengan adanya jam membaca setiap hari selama 30 menit, dapat meningkatkan budaya membaca di lingkungan SMP Negeri 13 Surakarta. Apabila siswa giat membaca, maka akan menambah ilmu pengetahuan dan dapat menambah pengalaman baca bagi siswa tersebut.

\section{Budaya Mutu Melayani Perpustakaan SMP Negeri 13 Surakarta}

Perpustakaan SMP Negeri 13 Surakarta selalu meningkatkan pelayanan bagi siswa dan guru yang menggunakan perpustakaan. Perpustakaan SMP Negeri 13 Surakarta telah memiliki sistem perpustakaan dengan menggunakan visual basic dan barcode untuk proses peminjaman dan pengembalian buku. Walaupun belum sepenuhnya digunakan, tetapi petugas perpustakaan selalu meningkatkan mutu layanan dari sistem manual menuju pemakaian sistem informasi berbasis komputer.

Perpustakaan SMP Negeri 13 Surakarta juga telah menggunakan AC untuk ruangannya dan diharapkan siswa yang berada di dalam ruang perpustakaan merasa nyaman. Televisi yang ada di perpustakaan dipergunakan untuk menambah wawasan tentang berita yang sedang hangat di tanah air ataupun luar negeri. Sarana dan prasarana di perpustakaan SMP Negeri 13 Surakarta juga telah ditingkatkan dari tahun ke tahun. Meja dan kursi yang semula berjumlah 10 buah sekarang telah menjadi 40 kursi dan 15 meja panjang agar guru dapat membawa siswa ke perpustakaan untuk proses belajar-mengajar. Perpustakaan SMP Negeri 13 Surakarta juga telah dilengkapi dengan wifi yang titik aksesnya berada di ruang perpustakaan. Dengan adanya wifi, akan dapat mempermudah siswa dan guru untuk mengakses internet dengan cepat dan dapat mengetahui informasi melalui internet. Petugas perpustakaan juga telah membuat piket guru dan piket siswa yang berasal dari OSIS untuk menjaga kelancaran pengunjung dalam membaca dan melakukan peminjaman, serta pengembalian buku. Ada guru piket setiap hari yang telah dijadwal untuk menjaga pada waktu istirahat pertama dan kedua.

\section{PENUTUP}

Budaya peduli dan budaya mutu melayani di perpustakaan SMP Negeri 13 Surakarta diwujudkan dengan melakukan beberapa 
langkah konkret yang bertujuan untuk perpustakaan untuk mengganti penggunaan memajukan perpustakaan. Siswa tidak perlu manual pada proses peminjaman dan membeli buku pelajaran karena setiap siswa pengembalian buku, serta data anggota mendapat pinjaman buku pelajaran dari sekolah perpustakaan, sehingga dapat mewujudkan selama satu tahun, setelah selesai satu tahun sekolah yang menyenangkan dan siswa dapat pelajaran, buku tersebut dikembalikan.

Budaya mutu melayani di perpustakaan SMP Negeri 13 Surakarta diwujudkan dengan peningkatan mutu layanan kepada pengunjung menikmati proses pembelajaran, merasa nyaman berada di lingkungan SMP Negeri 13 Surakarta, terutama jika siswa berada di ruang perpustakaan.

\section{DAFTAR PUSTAKA}

Anonim. 2013. "Pengertian Mutu Pendidikan”. Diakses dari http://seputarpendidikan003.blogspot. co.id/2013/06/pengertian-mutu pendidikan.html, tanggal akses 30 Januari 2016.

Bahari, Agi. 2015. "Kriteria/Ciri-ciri Sekolah yang Menyenangkan, Memberi Pilihan Tantangan Bermakna bagi Siswa”. Diakses dari http://www.edukasippkn.com/2015/04/kriteria-ciriciri-sekolah-yang.html, tanggal akses 30 Januari 2016.

Dhimas. 2010. "School Rules". Diakses dari https://luciuslawliet.wordpress.com/tag/sekolahyang-menyenangkan/, tanggal akses 30 Januari 2015.

Sumut, LPMP. 2013. "Pengembangan Budaya Mutu di Sekolah Menuju Sekolah Unggul”. Diakses dari http://lpmp-sumut.or.id/1/wp-content/uploads/2013/04/pengembangan-budaya-mutudi-sekolah, tanggal akses 30 Januari 2016.

Wahyuningtyas, Hera. 2015. “Membudayakan Peduli Sejak Dini”. Diakses dari https://www.scout. org/node/52163, tanggal akses 30 Januari 2016. 